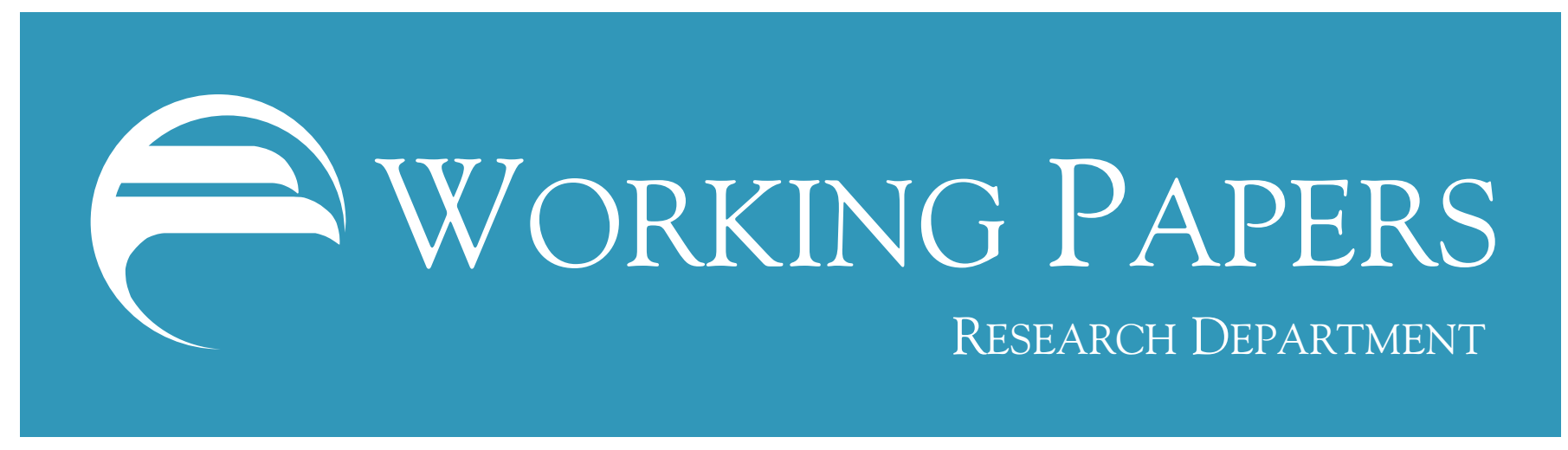

\title{
WORKING PAPER NO. 03-18 POSTWAR PERIOD CHANGES IN EMPLOYMENT VOLATILITY: NEW EVIDENCE FROM STATE/INDUSTRY \\ PANEL DATA
}

Gerald Carlino

Federal Reserve Bank of Philadelphia

Robert DeFina

Villanova University

Keith Sill

Federal Reserve Bank of Philadelphia

August 2003

\section{Federal ReserVe BANK of PhILAdELPHIA}




\title{
Postwar Period Changes in Employment Volatility: New Evidence From State/Industry Panel Data
}

\author{
Gerald Carlino \\ Federal Reserve Bank of Philadelphia \\ Robert DeFina \\ Villanova University \\ Keith Sill \\ Federal Reserve Bank of Philadelphia
}

August 2003

The opinions expressed in this paper are those of the authors and do not necessarily represent those of the Federal Reserve Bank of Philadelphia, the Federal Reserve System, or Villanova University. 


\begin{abstract}
Many recent studies have identified a decline in the volatility of U.S. real output over the last half century. This study examines a less discussed and analyzed trend, but one as significant as the drop in output volatility, namely a substantial decline in employment volatility during the postwar period. Using a new panel data set covering industry employment by state since 1952 we find that a large decline in employment growth volatility began in the early 1950s and largely ended by the mid to late 1960s. This study also illuminates the geographical dimension of the declines, an aspect that has heretofore been unexamined. The data indicate that all states have shared in the volatility decline, although the magnitudes have differed.

A pooled cross-section/time-series model indicates that fluctuations in statespecific (state level differences in demographic and industrial composition) and macro variables (e.g., changes in monetary policy regimes) have each played a potentially substantial role in explaining volatility trends. We find that state-specific forces account for between 1 percent and 24 percent of the variations in employment volatility across time and space. Macro variables account for between 30 percent and 76 percent of the movements in employment volatility, a range broadly consistent with the findings of Stock and Watson (2002). An important finding of this study is that "unknown forms of good luck," in the form of smaller shocks to employment, account for between 1 percent and 10 percent of the observed fluctuations. This latter finding suggests a reduced role for unknown forms of good luck in describing the postwar decline in volatility compared to the findings in Stock and Watson's (2002) analysis of the variance of real output growth.
\end{abstract}




\section{Introduction}

Many recent studies have identified a decline in the volatility of U.S. real output over the last half century. The standard deviation of quarterly real GDP growth, for example, has fallen by a factor of three over the post-war period. Several researchers have argued that a structural break in output volatility occurred in the mid-1980s, although some describe the decline as more steady and protracted [see, e.g., Kim and Nelson (1999), McConnell and Perez-Quiros (2000) and Blanchard and Simon (2001).] Reasons for the decline have proved difficult to verify empirically. The most obvious candidates, such as changes in the composition of aggregate demand away from durable goods and toward services, decreases in the volatility of investment spending, shifts in the behavior of inventories, and better monetary policy, have offered some, but relatively little, explanatory power.

This study examines a less discussed and analyzed trend, but one as siginificant as the drop in output volatility: a substantial decline in employment volatility during the postwar period. While this might be viewed simply as the other side of the output volatility coin, it is not. For example, evidence provided later in the paper reveals that a large decline in employment growth volatility began in the early 1950s and largely ended by the mid to late 1960s. That is, the drop in employment volatility appears to have largely ended before the drop in output volatility began.

This study contributes to the literature on the volatility decline in several ways. First, it employs a new quarterly data set on employment by state and industry. Second, the study illuminates an aspect of the decline in volatility that has been unexamined, namely, the geographical dimension of the declines. Indeed, our data indicate that while 
all states have shared in the volatility decline during the sample period, the magnitudes have differed. The unevenness of the declines raises the possibilities that either the aggregate sources of volatility swings have produced differential effects across states or that the underlying sources themselves are specific to states.

Third, the pooled cross-section/time-series data permit us to estimate a richer model of volatility than those based solely on time series data. The pooled model includes time-varying state-specific influences, such as the age and gender composition of the population and state industrial structure, which permits differential state-level effects for a wide array of macro variables. These macro forces include changes in monetary policy operating procedures, fiscal policy and multifactor productivity, the degree of openness of the U.S. economy, the degree of unionization, and episodes of energy price shocks.

Our findings reveal that both the state specific and macro forces have contributed significantly to employment volatility. Macro forces explain between 30 percent and 76 percent of the fluctuations in employment volatility. This range is wider than that presented in Stock and Watson (2002), who estimate that macro variables account for between 40 percent and 60 percent of the decline in output volatility. Stock and Watson also attribute 40 percent to 60 percent of the moderation in output volatility to "unknown forms of good luck that manifest themselves as smaller reduced form forecast errors." By comparison, we find that such unidentifiable good luck accounts for at most 10 percent of the drop in employment volatility. Thus our upper bound estimate is well below their lower bound. In part, the reduced role for smaller prediction errors might reflect our introduction of state-specific or cross-sectional variables into the analysis. 
These factors have contributed between 1 percent and 24 percent to the moderation in volatility.

\section{Literature Review}

Several recent studies have examined various aspects of the observed decline in volatility for many macroeconomic variables. McConnell and Perez-Quiros (2000) used an assortment of empirical strategies to measure output volatility, including the estimation of AR1 and Markov regime-switching models of output growth, and found that there was a one-time decrease in U.S. real output volatility in 1984Q1. They investigated possible causes for the decline, ruling out shifts in the composition of aggregate demand and settling tentatively on a changed relationship between inventories and sales.

Stock and Watson (2002) used VARs to examine the time-series behavior of volatility for 168 macroeconomic variables during the period from the early 1960 s to the present $^{1}$ They find that the decline in volatility is broad-based and that, rather than a smooth trend decline, the drop in volatility is better characterized as a trend break that occurred around 1984. Stock and Watson (2002) argue that between 20 percent and 30 percent of the decrease has resulted from improved monetary policy. The remaining decline is attributable to smaller output shocks, which they term "good luck." Kim and Nelson (1999) also present evidence that aggregate output volatility experienced a onetime decline in 1984.

\footnotetext{
${ }^{1}$ Stock and Watson (2002) provide an extensive review of the literature on the volatility decline for macroeconomic variables.
} 
Blanchard and Simon (2001) also examined the volatility of aggregate real output growth during the postwar period, using rolling standard deviations of actual growth and standard errors from rolling AR1 regressions to gauge volatility. They present evidence that, regardless of the volatility measure, volatility declined steadily and persistently during the post-war period, "from about 1.5 percent a quarter in the early 1950 s to less than 0.5 percent in the late 1990s." Their results indicated that the decline is accounted for by reductions in the residual variance of output growth and is not a function of changes in the persistence of output shocks (i.e., the estimated AR1 coefficients.). Blanchard and Simon (2001) further conclude that the decline in real output volatility is not simply due to the absences of large shocks during the past two decades. Tests of the different hypotheses studied by McConnell and Perez-Quiros (2000) failed to find a major reason for the decline.

A different strand of the literature has used cross-sectional data for states and metropolitan areas to analyze the role of industrial diversification on cross-sectional differences in output and employment stability and instability. These studies typically focus on the average unconditional volatility of a variable's quarterly or annual growth over some single time period (e.g., 1970 to 1990.) Thus, they lack time-series variation in volatility and so cannot offer evidence on the reasons for any trend decline. It is conceivable, though, that time variations in the cross-section variables are important determinants of changing aggregate trends.

The findings of the cross-section studies are somewhat mixed, but the bulk of the evidence indicates that more industrially diverse locations tend to be associated with lower employment volatility. For example, using employment data for metropolitan 
areas, Siegel (1966), Conroy (1975), Kort (1981) and Malizia and Ke (1993) find that industrial diversity explains a significant share of the differences in volatility across metropolitan areas. Wundt (1992) and Sherwood-Call (1990), using state level data, also find evidence that industrial diversification reduces economic volatility. Some studies, however, find no evidence favoring the diversity-stability view [Jackson (1984) using multi-county aggregates for Illinois, and Attaran (1986) for all states.]

Our study compliments both the macroeconomic and regional literature in that we exploit the cross-sectional variation in employment volatility as well as the time-series dimension in analyzing postwar period changes in employment volatility. As we will document, employment volatility has fallen over time in all states for which we have data, although to differing degrees. Thus it is important to consider both the time-series dimension and the cross-sectional aspect of the changes in volatility.

We use new data on state-level employment in eight one-digit SIC categories to estimate pooled cross-section time-series models of employment volatility. The data have a quarterly frequency and extend back to 1952. Thus our sample period is longer than typically used in past regional and aggregate studies. For example Malizia and Ke's sample runs from 1972-88, and Sherwood-Calls' sample covers the period 1963-86.

\section{Measuring Employment Volatility}

The data we use for this study were obtained by special order from the U.S. Labor Department. The data set consists of quarterly measures of nonagricultural employment in eight one-digit sectors for each of the 48 continental U.S. states extending back to 1952 . In total, 38 of the 48 states have complete data for all sectors, while the 
remaining 10 states are missing early data for one or more sectors. data on the 38 states for which full data are available, and by doing so adds 40 additional years of data for the large majority of states (using all 48 states requires starting the analysis in 1981.) The cost of doing so - excluding the 10 states with incomplete data appears small. In 1982:1, one of the first quarters when data for all 48 states are available, the 38 states in this study comprised 81 percent of total employment. It is thus highly likely that our analysis captures a substantial fraction of employment variation. Consequently, for present purposes, aggregate employment is defined as the 38-state sum of state-level employment.

Our measure of volatility is based on log first differences of the employment series. As displayed in Figure 1, the mean unconditional volatility of state level employment, as measured by rolling 20-quarter standard deviations of employment growth, declined dramatically between 1952 and the late 1960s. Volatility then rose until the early 1980s, at which point it began to fall once again. As we have discussed, we will exploit both cross-sectional and time-series changes in employment volatility to understand these overall movements.

These general trends are also visible using estimates of the conditional variance of employment. Following many previous studies [e.g., McConnell and Perez-Quiros (2000), Blanchard and Simon (2001), Ghosh and Wolf (1997) and Hess and Iwata (1997)] we model the systematic component of employment growth as an AR(1) process, estimated using rolling samples of 20 quarters. Hess and Iwata (1997) make an

\footnotetext{
${ }^{2}$ The 10 states with missing observations are Connecticut, Delaware, Illinois, Massachusetts, Michigan, Maine, Minnesota, Maryland, Rhode Island, and Utah. The BLS employment series has state level data for manufacturing; services; trade; government; transportation, communication, and public utilities; mining, construction; and finance insurance and real estate.
} 
especially forceful empirical case for this approach. Our model for the dynamic evolution of employment growth then is:

$$
y_{t}=\rho y_{t-1}+\varepsilon_{t}
$$

where $y_{t}$ is employment growth. Our estimates of random employment growth shocks (the $\varepsilon_{t}$ 's) and of the error variance come directly from estimates of equation (1).

Figure 2 shows the residual standard deviation of the 38-state aggregate employment growth for the period 1952:1 to 1995:4. The series displays a pattern very similar to that for the unconditional volatility. It falls from a bit under 1.4 percent in 1952 to just under 0.4 percent in 1995 . The majority of the drop in volatility occurs between 1952 and the late 1960s, when the standard deviation falls to almost 0.5 percent. Beginning in the 1970s, employment volatility reversed its previously declining trend and nearly doubled. This rise in volatility coincides with the generally poor economic outcomes of the 1970s, during which the economy experienced rising inflation and slow growth. From the early 1980s on, however, volatility generally declined as economic performance improved relative to that of the 1970s.

Closer inspection of the data shows some differences between the patterns of the unconditional volatility, $\left(\sigma_{y}^{2}\right)$ and the conditional volatility, $\left(\sigma_{\varepsilon}^{2}\right)$. Most notably, after 1968, the difference between the two series widened and generally remained wider for the remainder of the sample. The greater difference between the series in more recent years reflects greater persistence in the AR1 process (discussed below.)

The general decline in conditional volatility was widespread across states and industry sectors. A set of histograms of conditional state-level employment volatility at 
the beginning, middle and end of our sample -- 1952:1, 1971:3, and 1995:4 -- illustrate this finding. The histograms for total state-level employment volatility at each of these three periods are shown Figure 3. Clearly, a significant change in the distribution of employment standard errors across states occurred between 1952 and 1971. In 1952, average employment volatility was much higher and the dispersion of volatility across states was fairly wide. Most states had employment volatilities of between 0.005 (0.5 percent) and 0.015 (1.5 percent). By 1971 virtually all states had employment volatilities of 0.5 percent or lower, and by 1995 the volatilities were lower still.

Figure 4 shows the change over time in the distribution of employment volatility across states for selected sectors -- manufacturing (Figure 4a) and services (Figure 4b). A general pattern is present across sectors that mimic the broad features of the change in distribution for aggregate employment volatility: the distributions tend to shift left and collapse over time. As Figure 4a shows, for manufacturing, average volatility across states in 1952 was about 0.026 (2.6 percent). By 1995, it had declined to 0.008 (0.8 percent). For the services sector, Figure $4 \mathrm{~b}$ shows average volatility declined from 0.015 (1.5 percent) in $1952: 1$ to 0.006 (0.6 percent) in $1995: 1$.

Changes in the Employment Process. As mentioned above, the data on unconditional and conditional employment volatilities indicate that the AR1 coefficient on the employment growth process [equation (1)] rose in the late 1960s. This point is

\footnotetext{
${ }^{3}$ The dispersion of volatilities across states, as measured by the coefficient of variation, fell 30 percent between 1952 and 1995, indicating that employment volatility became more similar across states over time. The downward trend was briefly interrupted, however, by increased volatility in the coefficient of variation during the late 1970s and early 1980s.

${ }^{4}$ For brevity, we show trends for manufacturing and services. Figures for other sectors are available from the authors on request.

${ }^{5}$ The general decline in dispersion of volatilities remains even after adjusting for the declining mean volatilities. That is, the coefficient of variation of state volatilities generally fell during the sample period. An exception is the 1980s during which the coefficient of variation was very erratic.
} 
made explicit in Figure 5, which graphs the mean value (38-state average) of the estimated $\rho$ coefficients from the state level time-varying AR1 regressions. The figure indicates that the AR1 coefficients increased slightly over time. The average value of $\rho$ was about 0.4 for the period 1952 to roughly the late 1960 s and has risen to about 0.43 since then. This relatively small, but statistically significant, upward movement in the $\rho$ coefficient implies a rise in unconditional employment volatility relative to the conditional volatility because the variance of $y_{t}$ from equation (1) is $\sigma_{\varepsilon}^{2} /\left(1-\rho^{2}\right)$.

A higher $\rho$ means that a given shock has a more persistent effect on employment. Given its timing, a plausible explanation for the increase in persistence can be found in the changing nature of the shocks hitting employment. One view is that prior to the 1970s demand shocks were more prevalent and more important sources of economic volatility than aggregate supply shocks. Especially during the 1970 s and early to mid1980s, the situation reversed. Even in the 1990s, the emphasis on productivity increases supports a view that aggregate supply shocks remained important, at least more important than in the pre-1970 period. To the extent that aggregate supply shocks have long-lasting or even permanent, effects, their increased presence would cause the average level of persistence to rise [see, e.g., Hamilton $(1983,1996)$.

In any case, the implication of most direct relevance is that the rise in $\rho$ cannot be a source of the trend decline in unconditional volatility. The decline must stem either from decreases in the average size of shocks hitting employment or from changes in the shape of the distribution of those shocks.

\footnotetext{
${ }^{6}$ We regressed the 38-state average AR(1) coefficient series on a dummy variable for which 1966:1 and
} 


\section{The Postwar Decline in Conditional State Employment Volatility}

In this section, we study possible sources of the observed fluctuations in conditional employment volatilities. We first identify economic and demographic trends that might have driven the observed variations in employment volatility, documenting the trends and suggesting theoretical reasons for their importance. We then quantify the effects of each variable on employment volatility using state-level pooled cross-section/time series models.

Changes in the size of employment shocks. One direct influence on the size of the error variance is the magnitude of the underlying employment shocks themselves. That is, volatility may have fallen simply because of a reduction in the size of shocks hitting employment growth. Existing studies have produced conflicting evidence. Blanchard and Simon (2001) argue that the observed decline in output volatility had little to do with changes in the size of output shocks, while Friedman (2001) and Stock and Watson (2002) provide evidence that output shocks have decreased in size, and that these reductions have contributed significantly to lower output volatility.

A preliminary analysis suggests that smaller shocks could be important in accounting for lower volatility. We calculated the mean absolute error of shocks to total state employment across the 38 states. The resulting series is plotted in Figure 6. The mean absolute error exhibits a profile that is roughly similar to that for the mean conditional volatility across states. The error falls from about 0.008 in the early 1950 s to about 0.006 in the late 1960s. It then rises to 0.009 before falling in the 1980s and 1990s to about 0.0045 , half its peak value. Changes in the size of employment growth shocks thus tentatively appear to underlie some of the variation in employment growth volatility.

after equals unity; the coefficient was highly significant (t-statistic of 4.45). 
Greater stability in macro economic fundamentals. To some extent, the smaller shocks are themselves a function of greater stability in the fundamental determinants of real economic activity. Many reduced form macro models imply that volatility in real activity such as employment arises from volatility in exogenous policy actions and productivity [see, e.g., Taylor (1999).] Indeed, three variables that have received attention in the relevant literature are monetary policy, fiscal policy, and multifactor productivity.

Figures $7 \mathrm{a}$ and $7 \mathrm{~b}$ show the volatilities of growth in real government purchases and in multifactor productivity. Volatilities are computed using the regression standard errors from rolling 20-quarter AR(1) models, the identical procedure used to measure employment growth volatility. 그 The figures show that each series generally declined during the sample period, and that each appears to mirror other aspects of employment growth volatility. The volatility in multifactor productivity, for instance, trends down until the late 1960s, after which it rises for a while before falling again throughout the 1980s. Apart from its downward trend, the volatility in real government purchases is less obviously linked to employment growth volatility movements. It appears though that the underlying pattern in the volatility of these variables appears to mirror the damped employment growth volatility.

\footnotetext{
${ }^{7}$ We display actual real government purchases rather than, say, full employment purchases or the full employment deficit, because these alternatives introduce unknown but perhaps significant degrees of measurement error. For example, construction of the high employment deficit requires an estimate of potential output, which is tricky at best. Furthermore, real purchases are largely exogenous with respect to contemporaneous employment growth and the degree of economic activity in general, and so the regression standard error represents a good proxy for present purposes. Similar logic holds for multifactor productivity growth; its regression standard error is not likely to be caused by contemporaneous employment growth volatility. For the purpose of the pooled regression estimations, we use a two-quarter lag of each variable to mitigate any endogeneity.
} 
Measuring the volatility in monetary policy is less straightforward. The Federal Reserve has followed an assortment of official operating procedures through the sample period, including targeting free reserves, non-borrowed reserves, monetary aggregates, and the federal funds rate. Using the regression standard error of any one of these variables is not easily defensible, nor is using the regression standard error from a "policy reaction function," since it is unclear what the left hand side variable should be.

Given these difficulties, we chose to represent shifts in monetary policy using dummy variables that represent different policy regimes. We identify policy regimes using the narrative analysis of Romer and Romer (2002a) that is based on FOMC policy directives. Their reading of the directives allowed them to identify four different policy regimes, characterized by reactions to inflation and output fluctuations. The regimes cover: 1952:1 to $1963: 4 ; 1964: 1$ to $1979: 3 ; 1979: 4$ to $1987: 3$; and $1987: 4$ to the present. In the first and third regime, the Romers find that the FOMC engaged in virtually no output stabilization, and instead focused on inflation. In the second regime, they found more active concern for output stabilization, but much less than in the fourth regime (the current period), in which the FOMC appears to be running a stronger countercyclical policy.

Although employment volatility fell during the sample period as a whole, Figure 2 shows two sub-periods - the mid-to-late 1970s and the mid 1980s - in which volatility spiked upward. Reasonable candidates for the sharp increases are the large oil price increases in the 1970s and the large decreases in the mid-1980s. Based on Hamilton's $(1983,1996)$ work, such large relative price changes require substantial labor

\footnotetext{
${ }^{8}$ Romer and Romer (2002a and 2002b) argue that the Fed always used a short-term interest rate as at least a supplementary target. They then characterize policy empirically using an estimated Taylor Rule, where the
} 
reallocations and could result in exceptionally large deviations from the employment growth process described by equation (1). Overall, our analysis identifies eight different quarters when the price of petroleum products experienced extraordinarily large increases or decreases: 1956:1, 1973:1, 1978:1, 1980:4, 1986:1, 1986:2, 1990:3, and 1991:1.

Structural changes in the economy. Variations in employment volatility across states and time might also stem from changes in the economy's structure. An often-cited example is the shift of employment from the goods-producing sector to the serviceproducing sector. As shown in Table 1, the average state share of employment in manufacturing fell from almost 26 percent in 1950 to less than 17 percent in 1990, while the share in services essentially doubled. Historically, the volatility of manufacturing employment has been higher than that of services, although the volatility of manufacturing relative to services has declined. By 1995 the ratio of manufacturing volatility to services volatility had fallen to 1.25 versus 1.7 in 1952:1. The shifting shares, other things equal, could contribute to more stable employment.

Other structural changes have occurred as well, although they have not usually been incorporated into analyses of volatility trends. Concerning the demographic structure of employment, the data in Table 1 reveal large increases in the fractions of the workforce that are: female; over age 64; with a college degree; and, nonwhite. To the extent that the different groups have varying degrees of labor force attachment, then the changing shares could affect volatility. Similarly, the fraction of employment that is unionized has dropped precipitously since 1950 , from 34.6 percent to 12.1 percent. The extent of unionization might matter because periodic collective bargaining agreements introduce wage rigidity, increasing the need for employment fluctuations to bear the burden of 
market equilibration. Finally, the U.S. economy has become increasingly open. Since 1950, total trade (real exports plus real imports) has risen as a fraction of real GDP from 6.4 percent to 17.7 percent. The increased international presence cuts volatility in different ways. On the one hand, greater imports increase the economy's automatic stability, while on the other hand greater exports increase the economy's exposure to potentially destabilizing foreign demand shocks. Any or all of these factors conceivably could have had an important influence on employment volatility.

Industrial concentration. A final issue that we address is how changes in industrial concentration affect volatility. The more diverse a state's industrial structure, the less susceptible they are to shocks to specific industries. The averaging out of shocks would then lead to lower total volatility. The boom and subsequent bust experienced by Silicon Valley provides a recent example of how lack of diversity results in high employment volatility. A commonly used measure of industrial diversity is the Herfindahl index. Table 1 shows that at the state level, the index has not changed much during the sample period, and so probably contributes little to observed volatility trends. An alternative index of industrial diversity (described below), often used in the regional economics literature, similarly showed little within-sample variation.

\section{Regression Analysis}

The Model. We empirically model the conditional volatility of state-level employment growth using a pooled cross-section/time-series regression model. The framework takes each state's employment growth volatility at a point in time as a separate observation, and relates it to the variety of macro, industrial and demographic variables identified in the preceding section. All macro variables are interacted with state 
dummy variables to permit macro shocks to have differential state effects. The model takes the form:

$\sigma_{i, t}=\alpha_{0}+\sum_{i=1}^{37} \beta_{i}$ state $_{i}+\sum_{j=1}^{J} \delta_{j} X_{i, t}+\sum_{i=1}^{38} \phi_{i}$ state $_{i} * Z_{t}+\gamma_{1} \sigma_{i, t-1}+\gamma_{2} \sigma_{i, t-2}+\varepsilon_{i, t}$

where: state $_{i}=1$ for state $\mathrm{i}$ and 0 otherwise;

$\sigma_{i, t}=$ regression standard error of employment growth in state $\mathrm{i}$;

$X_{i, t}$ is the set of explanatory variables for state $\mathrm{i}$ at time $\mathrm{t}$ (Cross-sectional variables):

- Share of employment in services for each state and time period;

- Index of industrial concentration, defined alternatively as a Herfindahl index or a sectoral diversity index that measures the variance of an industry's employment share in a state from the 38-state aggregate industry employment share,

- Percent of state employment that is female;

- Percent of state population: over 25 years old with college degree; nonwhite; and, aged 64 and over;

- Absolute value of the AR(1) errors for each state and time period;

- Two lags of $\sigma_{i, t}$.

$Z_{t}$ is the set of explanatory variables for the nation at time $t$ (Macro variables):

- Three dummy variables capturing the policy regimes identified by Romer and Romer (2002a). The three periods are: 1952:1 to 1963:4; 1964:1 to 1979:3; and, 1979:4 to 1987:3. The current regime covering 1987:4 to the present constitutes the reference period. These variables are interacted with state $_{i}$;

- Two-period lag of the volatility in multifactor productivity growth, measured as the regression standard errors from twenty-quarter rolling AR(1) processes. The

\footnotetext{
${ }^{9}$ The industrial diversity index is calculated as $I_{i, t}=\left(\sum_{j=1}^{8}\left(s s_{i, j, t}-n s_{j, t}\right)^{2}\right)^{1 / 2}$, where $s s_{i, j, t}$ is the share of employment in state $i$, industry $j$ at time $t$, and $n s_{j t}$ is the share of employment in industry $j$ for the 38-state aggregate at time $t$.
} 
variable is interacted with state $_{i}$. A two-period lag is used to reduce potential simultaneity problems;

- Two-period lag of the volatility in the growth of real government purchases, measured as the regression standard errors from twenty-quarter rolling AR(1) processes. The variable is interacted with state $_{i}$. A two-period lag is used to reduce potential simultaneity problems;

- Percent of national employment that is unionized interacted with state $_{i}$;

- Real total trade as a percent of real GDP interacted with state $_{i}$; and

- Oil shock dummy = 1 for 1956:1, 1973:1, 1978:1, 1980:4, 1986:1, 1986:2, 1990:3, and 1991:1, and 0 otherwise interacted with state $_{i}$.

Empirical results. The results are reported in Table 2. The regression was estimated for the period 1952:1 to 1995:4 using OLS with the White robust errors correction to account for heteroskedasticity. The table contains the estimated coefficients and the associated t-statistics. For brevity, we do not report the estimated coefficients on the state fixed effects.

The top section of the table contains the estimated coefficients for the crosssectional variables (the $X_{i, t}$ ). We find that the coefficient on the share of services is negative and significant, as expected (the higher the share of services the lower the employment volatility). Thus, we find evidence that the shift of employment from manufacturing to services has led to lower aggregate employment volatility. Accounting for other influences on employment volatility using a regression apparently allows the role of shifting employment shares to be seen more clearly than in other approaches. 10

\footnotetext{
${ }^{10}$ For comparability with other studies, we also conducted a counterfactual experiment in which we constructed a synthetic employment series holding constant industry shares at the observed beginning of the sample period levels. The volatility of the synthetic series closely mimicked that of the volatility of the actual series. This finding has led other researchers to conclude that changes in industry shares have played no role in volatility trends. Our regression analysis, which holds other factors constant, overturns this
} 
What do our findings imply for the diversity-stability hypothesis? Since the coefficient on the industrial concentration variable is insignificant, our results supports the views of Jackson (1984) and Attaran (1986) that a more diversified industrial structure does not reduce employment volatility.

Among the demographic variables, the percent of college graduates over 25 years old had positive and significant impacts on volatility. This finding is consistent with existing research that suggests more educated and experienced workers are more mobile. The percent nonwhite had a negative and significant impact. Finally, the coefficient on the absolute value of the state AR(1) errors is positive and highly significant. Earlier we noted that the average size of shocks is declining over time and, given its positive sign, helps to explain the downward trend in conditional volatility.

The lower section of the table contains the national variables that were interacted with the state dummies. The estimates are presented as the weighted sums of the individual coefficients (weights equal to sample average employment shares) with their appropriate t-statistics. The coefficients on the monetary policy dummy variables are positive for each of the periods, and all are highly significant. The estimated coefficients indicate that changes in monetary policy regimes have contributed to the trend decline in employment volatility, in that earlier regimes contributed less to stability than the current regime. These results support the narrative evidence about the conduct of policy described in Romer and Romer (2002a and 2002b), and the empirical findings in Stock and Watson (2002) who also conclude that monetary policy has produced a more stable economy.

result. We also conducted a counterfactual experiment using fixed state employment shares, but the synthetic and actual volatility series were almost identical. 
The coefficient on the conditional variance of multifactor productivity growth is positive and significant. The downward trend in its volatilities during the sample suggests that it has contributed to lower employment volatility. The volatility of growth in real government purchases has the expected positive sign, but is insignificant, while the percent of the workforce that is unionized has the wrong sign, but is insignificant. The increased openness of the U.S. economy had a positive effect on volatility, probably because of the greater exposure of the U.S. economy to foreign shocks and foreign labor market developments. Finally, as expected, periods in which large energy price changes occurred are associated with significantly higher employment volatility.

Accounting for the decline in volatility. We now quantify the contributions of the different types of explanatory variables to the observed changes in employment volatility. The total variance in employment volatility depends on the variance of the regressors and their co-variances. Since we cannot explicitly assign the magnitudes of the co-variances to any particular variable or set of variables, we estimate several auxiliary regressions that allow us to construct upper and lower bounds for the relative contributions of the macro and cross-sectional variables, and for the absolute AR(1) errors.

Specifically, to gauge the contribution of a set of variables, we first estimate a regression that includes only that set of variables. We then estimate a regression with all other variables excluding the set being examined. Finally, we estimate a regression that contains all explanatory variables. The adjusted $\mathrm{R}^{2}$ of the first regression gives the upper bound on the contribution of the set of variables, since it assigns to these variables all the explanatory power of the co-variances. The change in adjusted $\mathrm{R}^{2}$ from the second

\footnotetext{
${ }^{11}$ In an alternative estimation, the Herfindahl Index also insignificant.
} 
regression to the third provides the lower bound of the variables' contribution, since it assigns all explanatory power of the co-variances to the other variables. We conduct this analysis for three different sets of variables: the structural variables; the macro variables; and, the absolute values of the AR(1) errors. 12

The results of this exercise are shown in Table 3. The results indicate that the macro variables, including changing monetary policy, volatility in the growth in real government spending and multifactor productivity and energy price shocks (each interacted with the state dummies) explain between 25 percent and 72 percent of the total variation in employment growth volatility. This range encompasses the 40 percent to 60 percent range estimated by Stock and Watson (2002). A possible reason for our higher upper bound is the fact that we permit the macro variables to have state-specific effects, thereby increasing their potential explanatory power. Following Stock and Watson (2002), we isolated the contribution of monetary policy and of energy prices and multifactor productivity. We find that monetary policy accounts for between 8 percent and 63 percent of the movements in employment volatility. The estimated range is wider than that reported in Stock and Watson (20 percent to 30 percent). Oil-price shocks and the volatility in multifactor productivity account for between 4.0 percent and 36 percent of employment volatility. Again, this is a wider range than estimated by Stock and Watson (20 percent to 30 percent).

The cross-section variables explain between 1 percent and 24 percent of the total variation. It is thus possible, or even likely, that the movements in the cross-section variables played a nontrivial role in the shifting employment volatility. In fact, a

\footnotetext{
${ }^{12}$ For the purpose of this exercise, the two lags of the dependent variable are excluded from all regressions.
} 
noticeable result from the use of cross-sectional variation is a large reduction in the measured contribution of smaller employment shocks. The AR(1) errors were found to explain only between 1 percent and 10 percent of the variation. To the extent that this variable captures what Stock and Watson term "unknown forms of good luck," our results assign a much smaller role to it than theirs did (40 percent to 60 percent).

\section{Conclusion}

This study has documented a general decline in the volatility of employment measured at business-cycle frequencies and examined some of its possible sources. A unique aspect of our analysis is the use of panel data covering industry employment by state since 1952. These data provide a richer analysis than those based only on time series or on cross-section data. Indeed, the aggregate decline in conditional employment volatility was found to be widespread across states and industries, albeit to differing degrees. This variation across industries and states represents valuable information when statistically sorting out the causes of movements in volatility.

Our analysis indicates that fluctuations in cross-sectional and macro variables, and in the average size of employment shocks, have each played a potentially substantial role. The state-specific or cross-section variables explain between 1.0 and 24 percent of the variations in employment volatility. The macro variables (including changes in monetary policy regimes, the volatilities in real government purchases and multifactor productivity, and oil shocks) have generated 30 to 76 percent of the movements in employment volatility, a range broadly consistent with the findings of Stock and Watson (2002). Smaller shocks to employment have been responsible for between 1 and 10 percent of the observed fluctuations. This latter estimate substantially reduces the role 
played by "unknown forms of good luck," relative to the findings of Stock and Watson (2002). Finally, we find no evidence supporting earlier findings that a structural change in volatility occurred in 1984 . 


\section{References}

Attaran, Moshen (1986) "Industrial Diversity and Economic Performance in U.S. Areas," Annals of Regional Science, 20, pp. 44-54.

Blanchard, Olivier and John Simon (2001) "The Long and Large Decline in U.S. Output Volatility," Brookings Papers on Economic Activity, 1:2001, pp. 135-164.

Conroy, Michael E. (1975) "The Concept and Measurement of Regional Industrial Diversification," Southern Economic Journal, 41, pp. 492-505.

Friedman, Benjamin (2001) "The Long and Large Decline in U.S. Output Volatility: Comment and Discussion," Brookings Papers on Economic Activity, 1:2001, pp. 165171.

Ghosh, Atish R. and Holger C. Wolf (1997) "Geographical and Sectoral Shocks in the U.S. Business Cycle,’ NBER Working Paper No. 6180.

Hamilton, James D. (1983) "Oil and the Macroeconomy," Journal of Political Economy, 91, 1983, 228-48.

Hamilton, James D. (1996) "This is What Happened to the Oil Price-Macroeconomy Relationship," Journal of Monetary Economics 38, 215-20.

Hess, Gregory D. and Shigeru Iwata (1997) "Measuring and Comparing Business-Cycle Features,” Journal of Business and Economic Statistics, 15, 432-44.

Jackson, Randall W. (1984) "An Evaluation of Alternative Measures of Regional Industrial Diversification," Regional Studies, 18, pp. 103-112.

Kahn, James, Margaret McConnell, and Gabriel Perez-Quiros (2000) "The Reduced Volatility of the U.S. Economy: Policy or Progress?” Unpublished paper. Federal Reserve Bank of New York.

Kim, Chang-Jin, and Charles R. Nelson (1999) "Has the U.S. Economy Become More Stable? A Bayesian Approach Based on Markov-Switching Model of the Business Cycle," The Review of Economics and Statistics, 81, pp. 608-616.

Kort, John R. (1981) "Regional Economic Instability and Industrial Diversification in the U.S.," Land Economics, 57, pp. 596-608.

Malizia, Emil E., and Shanzi Ke (1993) “The Influence of Economic Diversity on Unemployment and Stability," Journal of Regional Science, 33, pp. 221-235. 
McConnell, Margaret and Gabriel Perez-Quiroz. (2000) "Output Fluctuations in the United States: What has Changed Since the Early 1980's?" American Economic Review, 90 (5), pp. 1464-76.

Romer C. and Romer D. (2002a) "The Evolution of Economic Understanding and Postwar Stabilization Policy," http://emlab.berkeley.edu/users/dromer/.

Romer C. and Romer D. (2002b) "A Rehabilitation of Monetary Policy in the 1950s," http://emlab.berkeley.edu/users/dromer/.

Sherwood-Call, Carolyn (1990) "Assessing Regional Economic Stability: A Portfolio Approach," Economic Review, Federal Reserve Bank of San Francisco, Winter, pp. 1726.

Siegel, Richard A. (1966) “Do Business Cycles Exist?” Western Economic Journal, 5, pp. 44-57.

Stock, James H., and Mark W. Watson (2002) "Has the Business Cycle Changed and Why?" NBER Working Paper No. 9127.

Taylor, John B. (1999) "Monetary Policy Guidelines for Inflation and Output Stability," in Benjamin F. Friedman, ed., Inflation, Unemployment, and Monetary Policy, (Cambridge: MIT Press)

Wundt, Bruce D. (1992) "Reevaluating Alternative Measures of Industrial Diversity As Indicators of Regional Cyclical Variations," Review of Regional Studies, 22, pp. 59-73. 
Table 1: Economic and Demographic Structure Variables

\begin{tabular}{|c|c|c|c|c|c|c|c|c|c|}
\hline Year & $\begin{array}{c}\text { Manufacturing } \\
\text { Share }\end{array}$ & $\begin{array}{c}\text { Services } \\
\text { Share }\end{array}$ & $\begin{array}{c}\text { Percent } \\
\text { Female }\end{array}$ & $\begin{array}{c}\text { Percent } \\
65 \text { and } \\
\text { Over }\end{array}$ & $\begin{array}{c}\text { Percent } \\
\text { Over 25 } \\
\text { with } \\
\text { College }\end{array}$ & $\begin{array}{c}\text { Percent } \\
\text { Nonwhite }\end{array}$ & $\begin{array}{c}\text { Percent } \\
\text { Union }\end{array}$ & $\begin{array}{c}\text { Total } \\
\text { Trade/GDP }\end{array}$ & $\begin{array}{c}\text { Herfindahl } \\
\text { Index }\end{array}$ \\
\hline 1950 & 25.9 & 12.1 & 27.0 & 7.6 & 5.7 & 11.8 & 34.6 & 6.4 & 0.199 \\
\hline 1970 & 24.0 & 15.8 & 40.3 & 9.8 & 10.1 & 13.7 & 31.0 & 10.5 & 0.196 \\
\hline 1990 & 16.8 & 24.0 & 56.5 & 12.7 & 18.9 & 15.3 & 12.1 & 17.7 & 0.193 \\
\hline
\end{tabular}


Table 2: Regression Results ${ }^{\mathrm{a}}$

(Sample period: 1952:1 to 1995:4)

\begin{tabular}{|c|c|}
\hline Variable & $\begin{array}{c}\text { Estimated Coefficient } \\
\text { (t-statistic) }\end{array}$ \\
\hline Constant & $\begin{array}{c}0.0008 \\
(0.6173) \\
\end{array}$ \\
\hline Services Share & $\begin{array}{c}-0.0048 * * * * \\
(-3.3012)\end{array}$ \\
\hline Industrial Concentration & $\begin{array}{c}0.0024 \\
(0.2457) \\
\end{array}$ \\
\hline Percent Female Labor & $\begin{array}{c}0.0000 \\
(0.4489)\end{array}$ \\
\hline Percent Population $>25$ with College Degree & $\begin{array}{c}0.0001 * * * \\
(3.8835)\end{array}$ \\
\hline Percent Population Nonwhite & $\begin{array}{c}-0.00001 * * \\
(-2.2879) \\
\end{array}$ \\
\hline Percent Population 65 and Over & $\begin{array}{l}-0.00003 \\
(0.00002) \\
\end{array}$ \\
\hline Absolute AR(1) Error & $\begin{array}{l}0.0508^{* * *} \\
(11.7966)\end{array}$ \\
\hline Variance of Employment $t_{t-1}$ & $\begin{array}{c}1.0683^{* * *} \\
(45.104)\end{array}$ \\
\hline Variance of Employment $t_{-2}$ & $\begin{array}{c}-0.1311 * * * \\
(-5.3101)\end{array}$ \\
\hline Monetary Policy Dummy, 1952:1 to 1963:4 & $\begin{array}{l}0.0006^{* * * *} \\
(5.0475)\end{array}$ \\
\hline Monetary Policy Dummy, $1964: 1$ to $1979: 3$ & $\begin{array}{l}0.0004 * * * \\
(4.5442)\end{array}$ \\
\hline Monetary Policy Dummy, 1979:4 to $1987: 3$ & $\begin{array}{l}0.0001 * * \\
(2.2219) \\
\end{array}$ \\
\hline Variance of Multi-Factor Productivity $\mathrm{t}_{\mathrm{t}-2}$ & $\begin{array}{l}0.0055 * * \\
(2.3015)\end{array}$ \\
\hline Variance of Real Government Purchases $\mathrm{s}_{\mathrm{t}-2}$ & $\begin{array}{c}0.0016 \\
(0.8662)\end{array}$ \\
\hline Percent Union & $\begin{array}{c}0.0005 \\
(0.9173) \\
\end{array}$ \\
\hline Total Trade/GDP & $\begin{array}{c}0.0046^{* * * *} \\
(3.5865)\end{array}$ \\
\hline Oil Shock & $\begin{array}{l}0.0001 * * \\
(2.1412) \\
\end{array}$ \\
\hline Adjusted $\mathrm{R}^{2}$ & 0.9771 \\
\hline
\end{tabular}

${ }^{a}$ All regressions include 37 state dummy variables. *,**,*** denotes statistical significance at the $10 \%$, $5 \%$, and $1 \%$ levels, respectively. Standard errors are adjusted using White's robust correction. 
Table 3: Accounting for the Decline in Employment Volatility

\begin{tabular}{|c|c|}
\hline Variables & Range of Contribution \\
\hline Cross-sectional Variables $^{\mathrm{a}}$ & 1 percent to 24 percent \\
\hline Macro Variables $^{\mathrm{b}}$ & 30 percent to 76 percent \\
\hline - Monetary Policy & 8 percent to 63 percent \\
\hline - Oil Price and Productivity & 4 percent to 36 percent \\
\hline Absolute Value of AR(1) Errors & 1 percent to 10 percent \\
\hline
\end{tabular}

${ }^{\text {a }}$ The cross-sectional variables include: state share of employment in services, an index of industrial concentration, the percent of state employment that is female, the percent of state population that is: (i) over 25 years old with college degree; (ii) nonwhite; and (iii) aged 64 and over.

${ }^{\mathrm{b}}$ The macro variables include: monetary policy variable, two-period lag of the volatility in the growth of real government purchases interacted with a state dummy, two-period lag of volatility in multifactor productivity growth interacted with a state dummy, an oil shock dummy interacted with a state dummy, the percent of the national employment that is unionized interacted with a state dummy, and percent of real national total trade as a percent of real GDP interacted with a state dummy. 
Figure 1: Aggregate Employment Rolling Standard Deviations (38 state total)

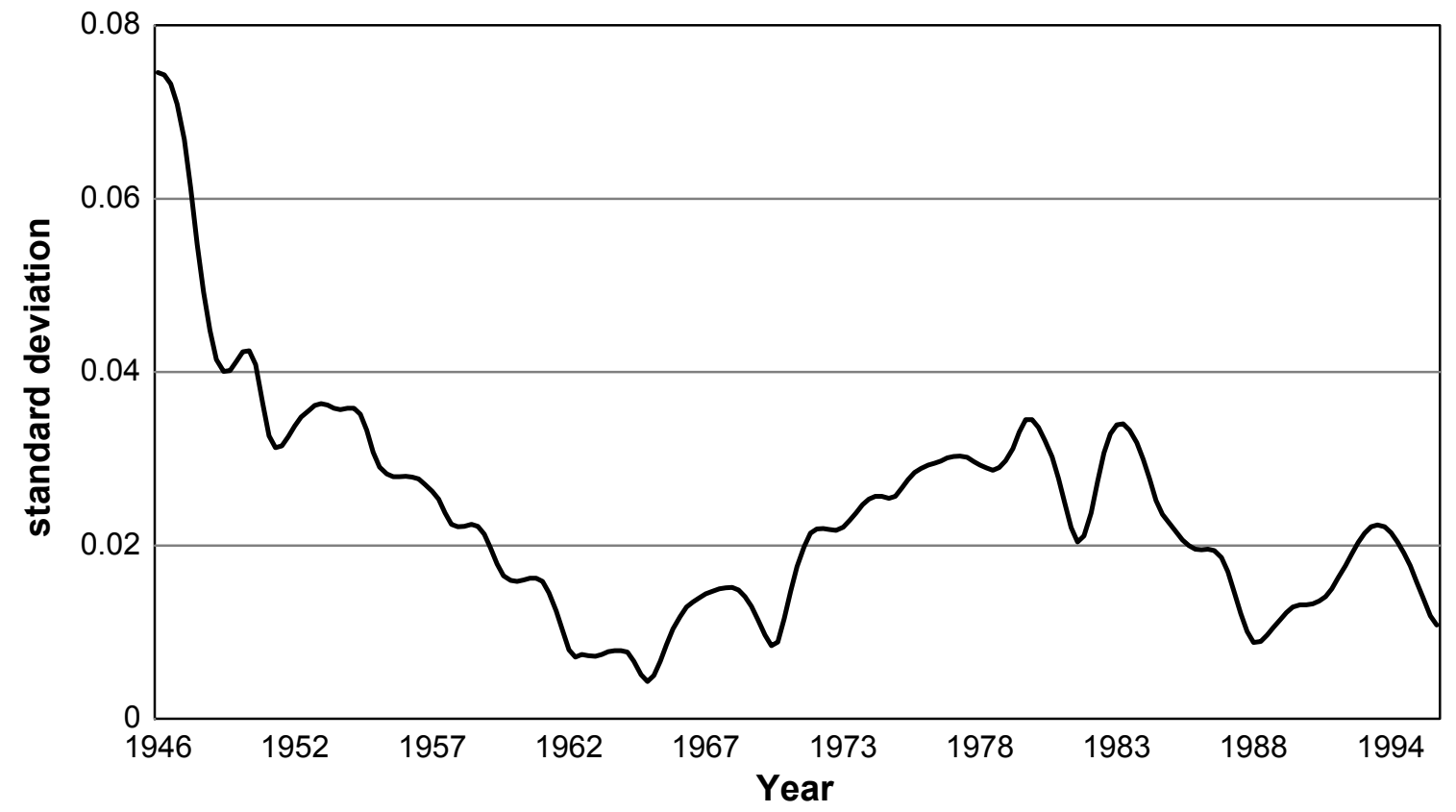


Figure 2: Aggregate Employment Rolling Regression Standard Errors (38 state total)

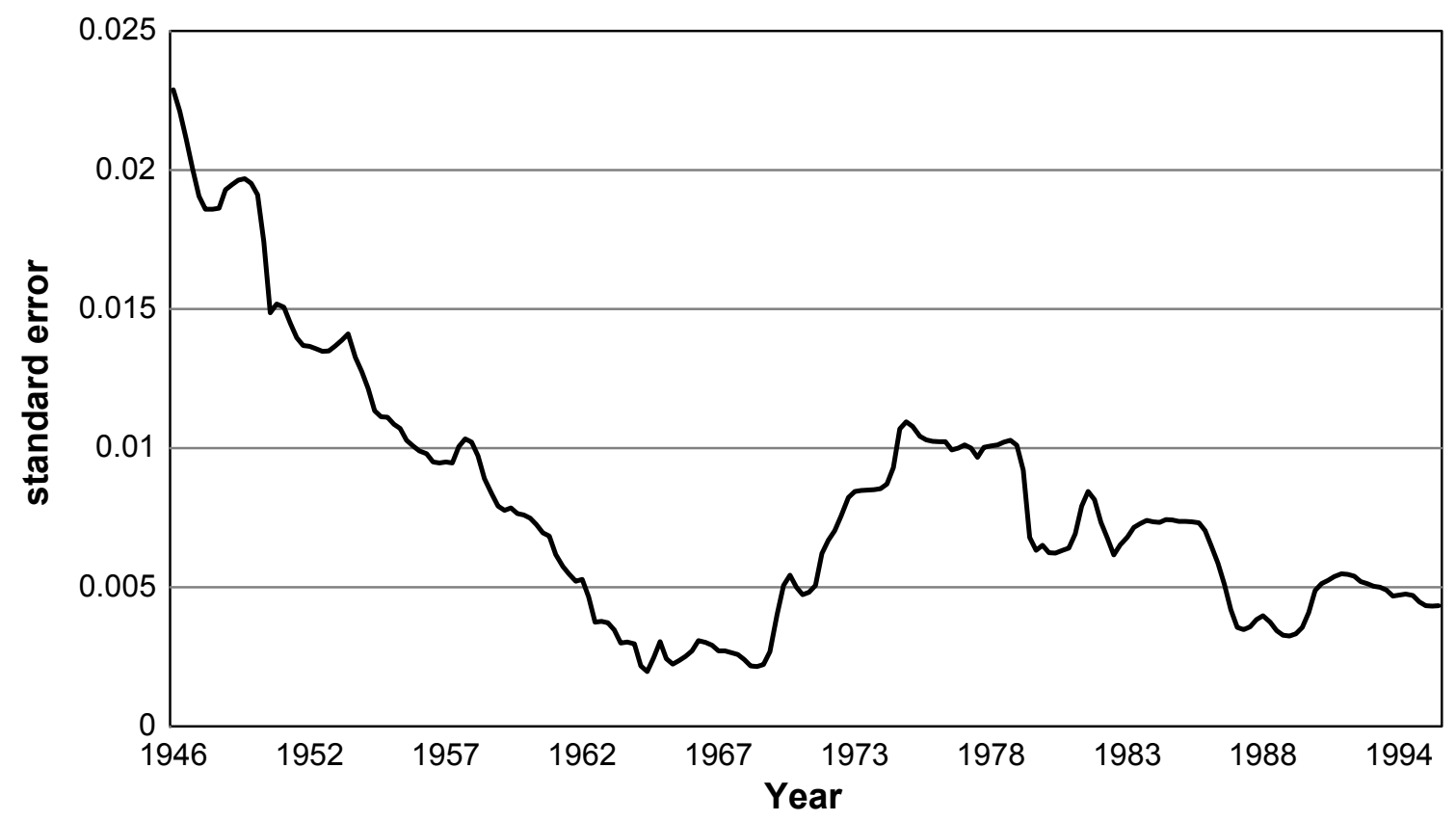


Figure 3: Distributions of Aggregate Employment Rolling Regression Standard Errors

(38 state total)

Panel A: 1947:1

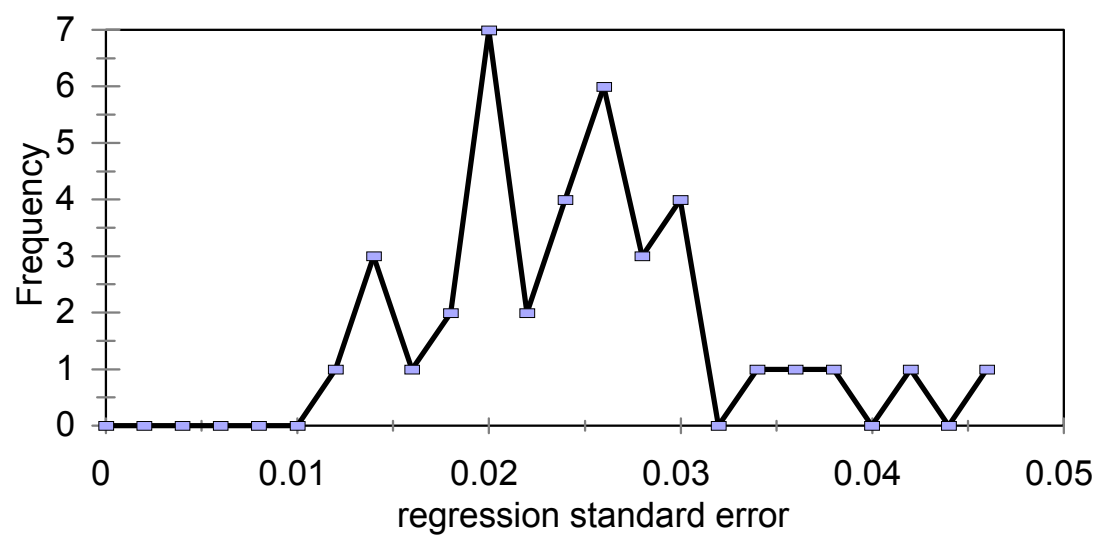

Panel B: 1971:3

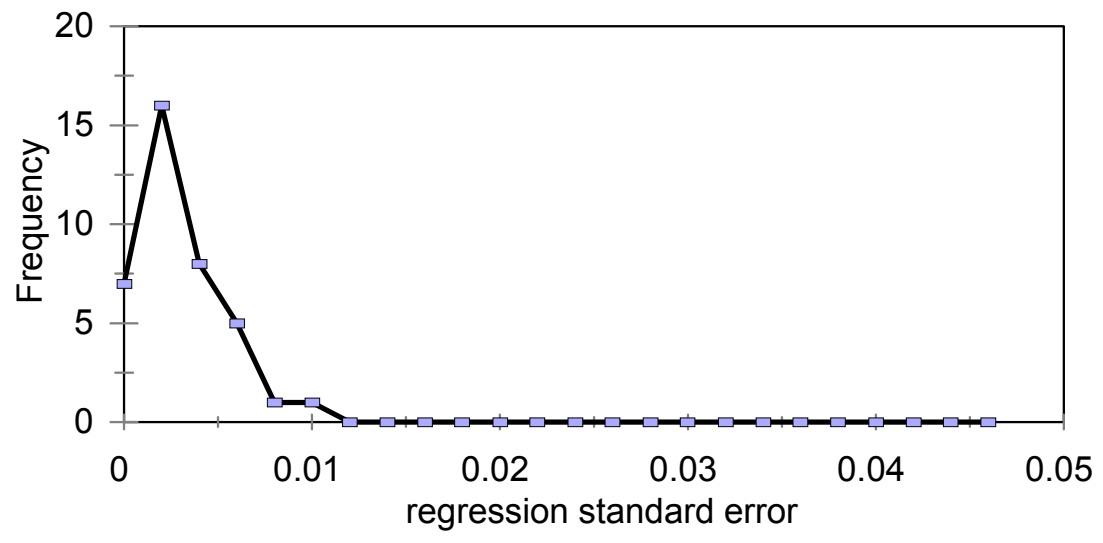

Panel C: $1995: 4$

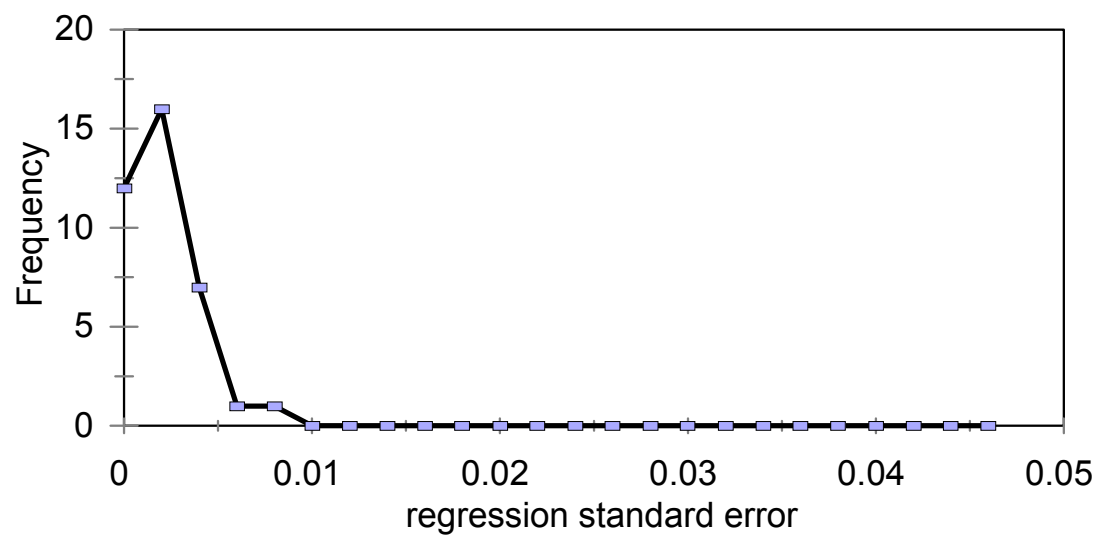


Figure 4a: Distributions of Manufacturing Employment Rolling Regression Standard Errors

(38 state total)
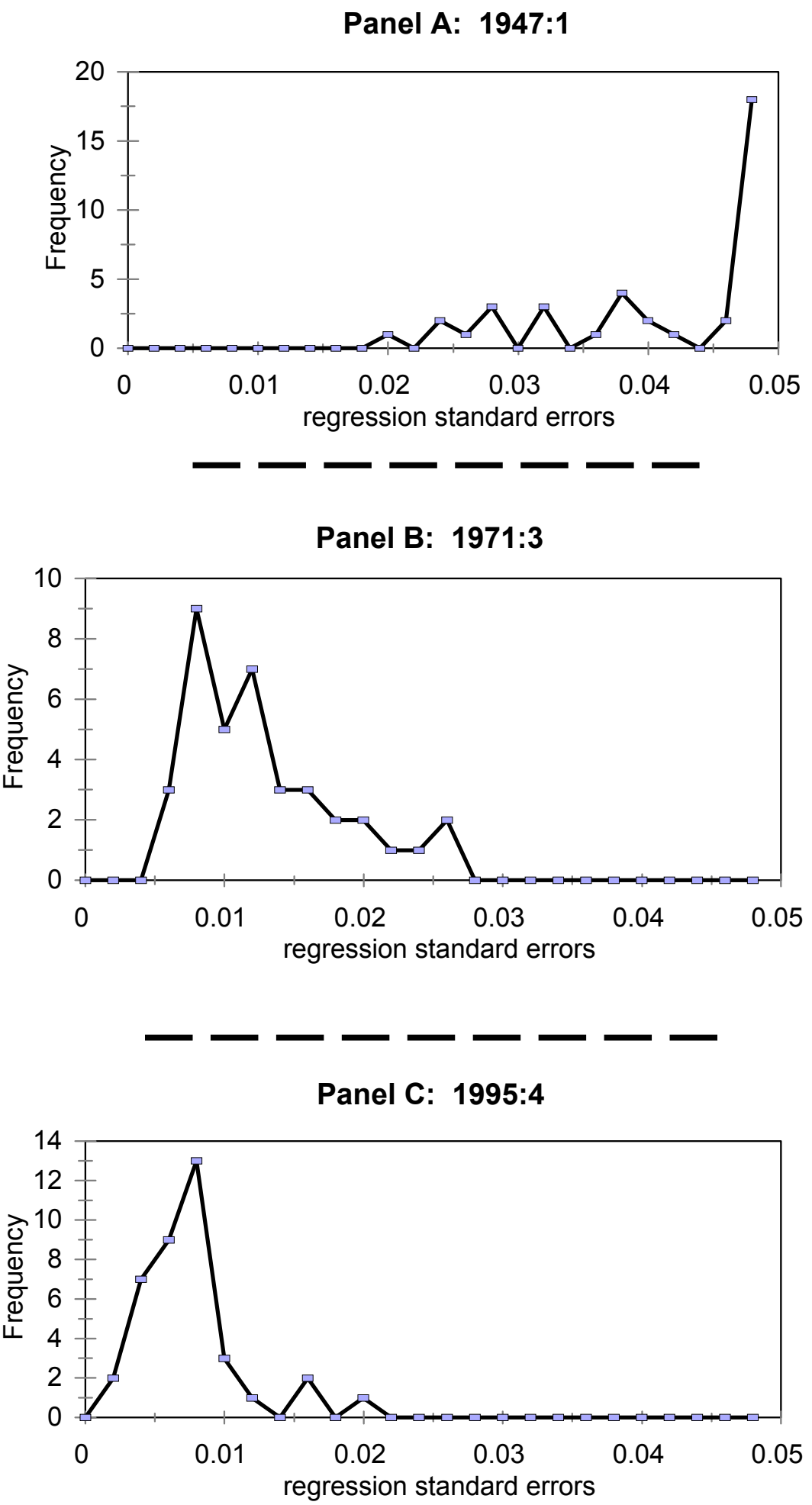
Figure 4b: Distributions of Services Employment Rolling Regression Standard Errors

(38 state total)

Panel A: 1947:1

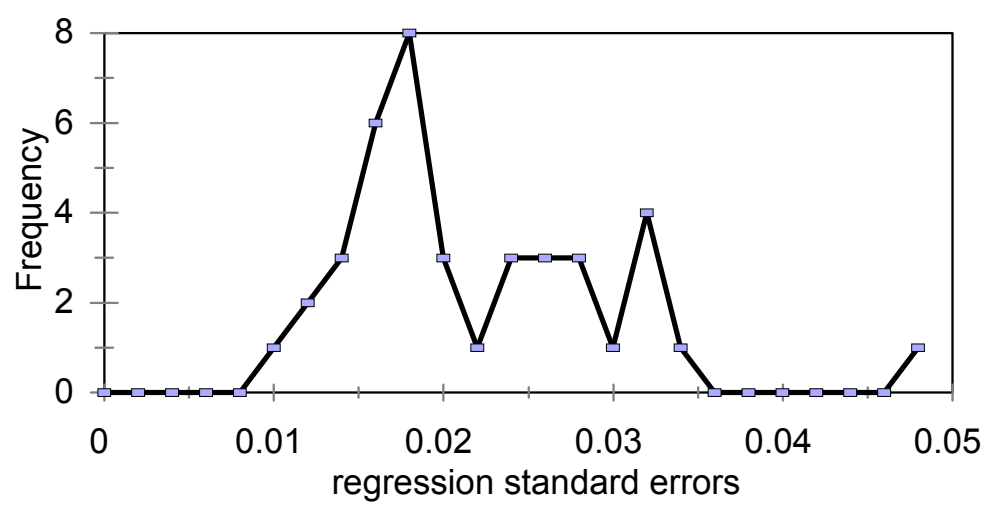

$-\div----$

Panel B: 1971:3
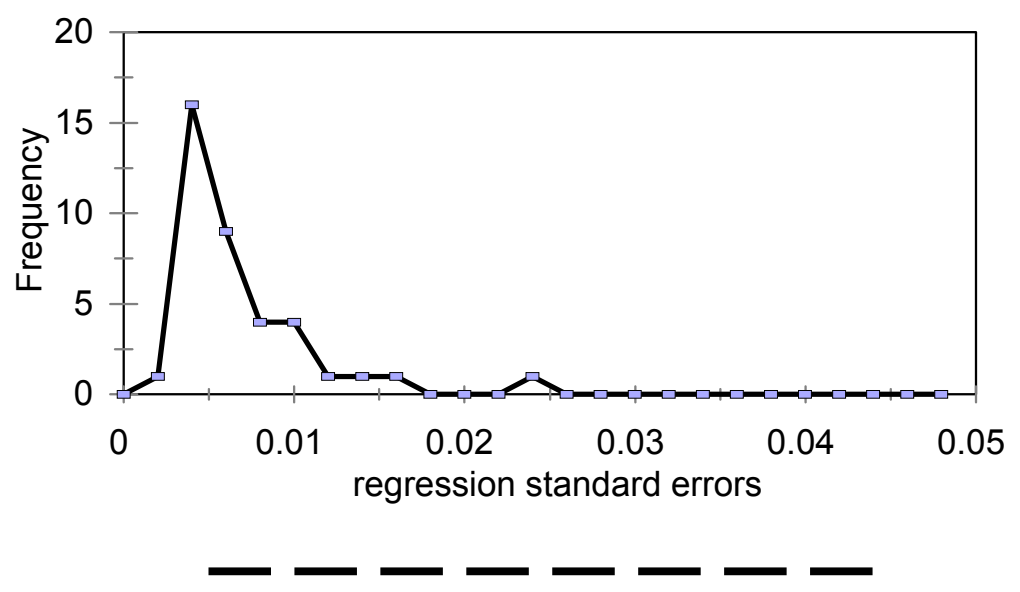

Panel C: 1995:4

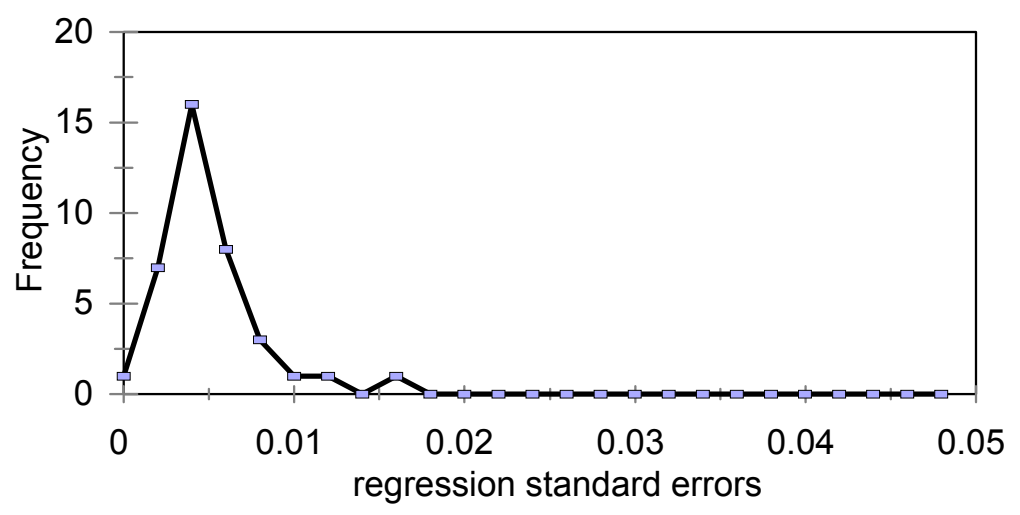


Figure 5: Coefficient of Variation for State Volatilities

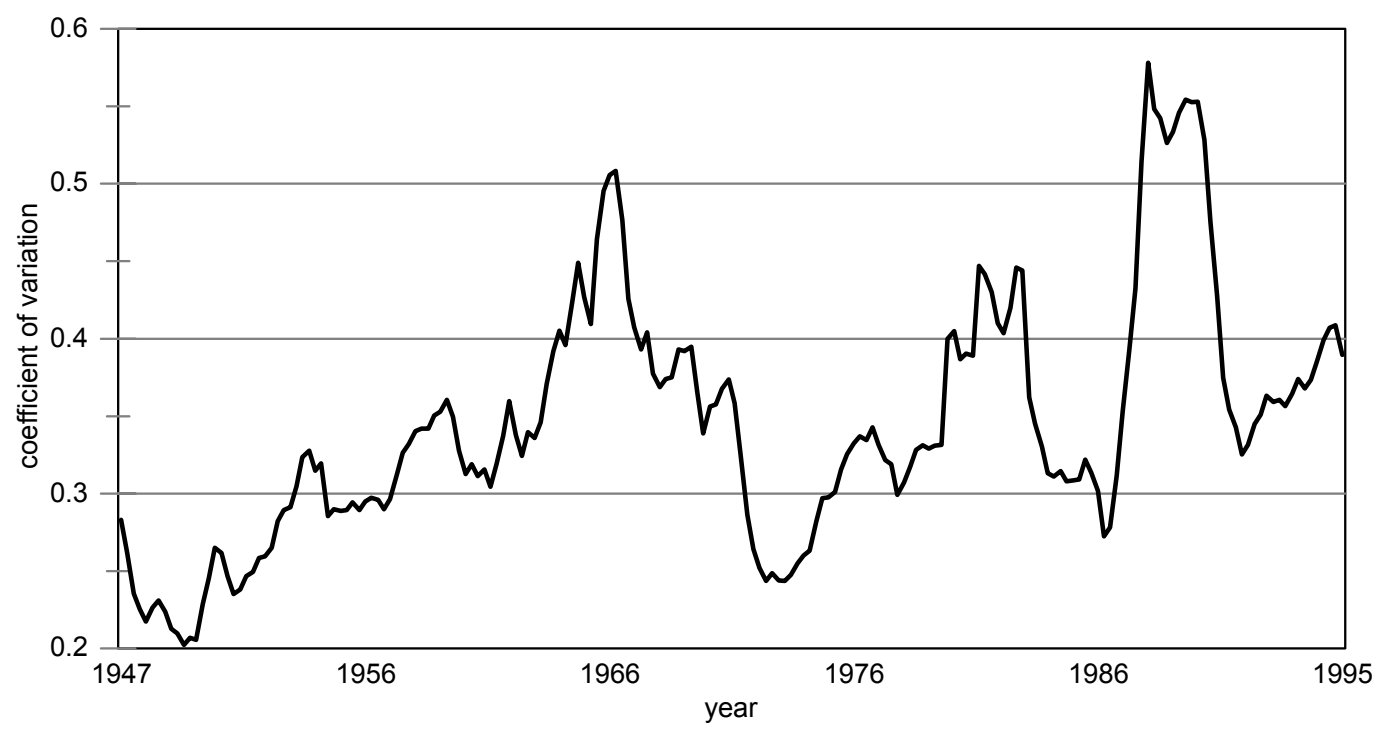


Figure 6: Average State AR1 Coefficients

(38 states, 12 quarter moving average)

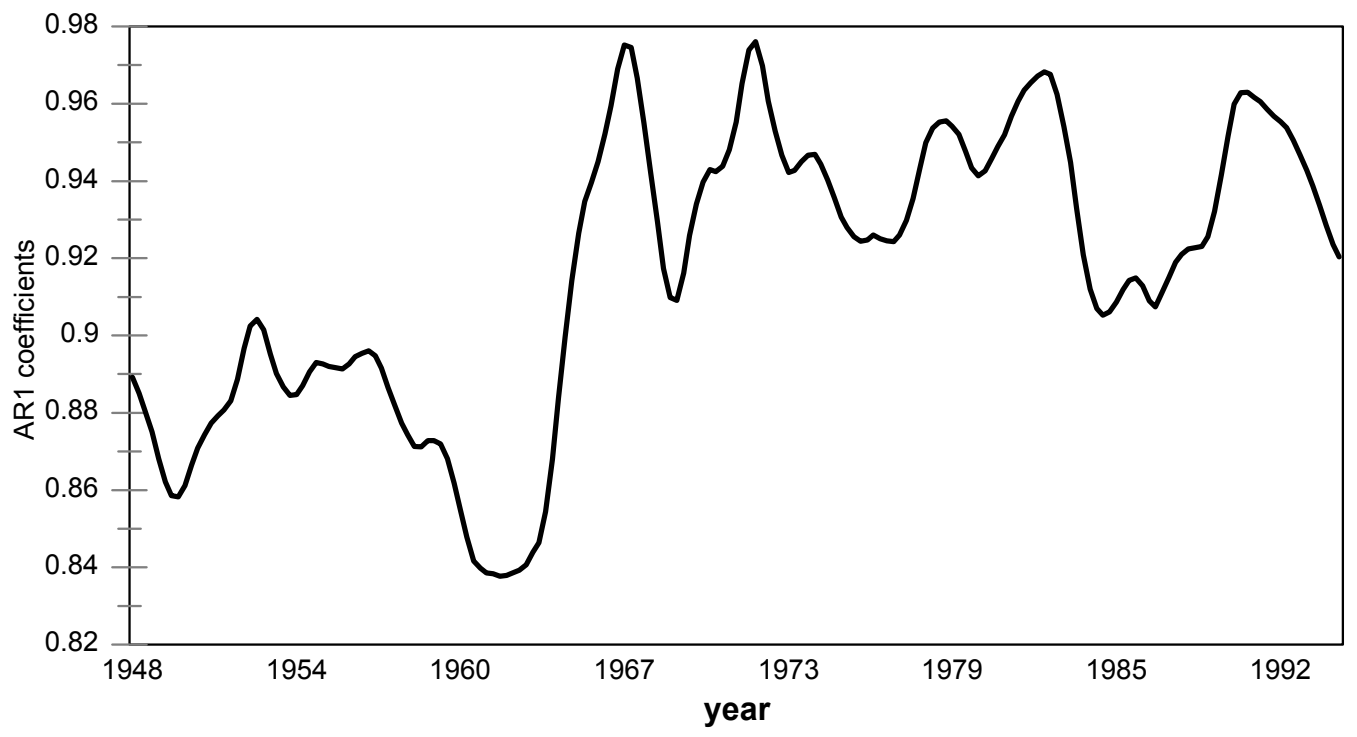


Figure 7a: State Mean Absolute Errors

(38 states, 12 quarter moving average)

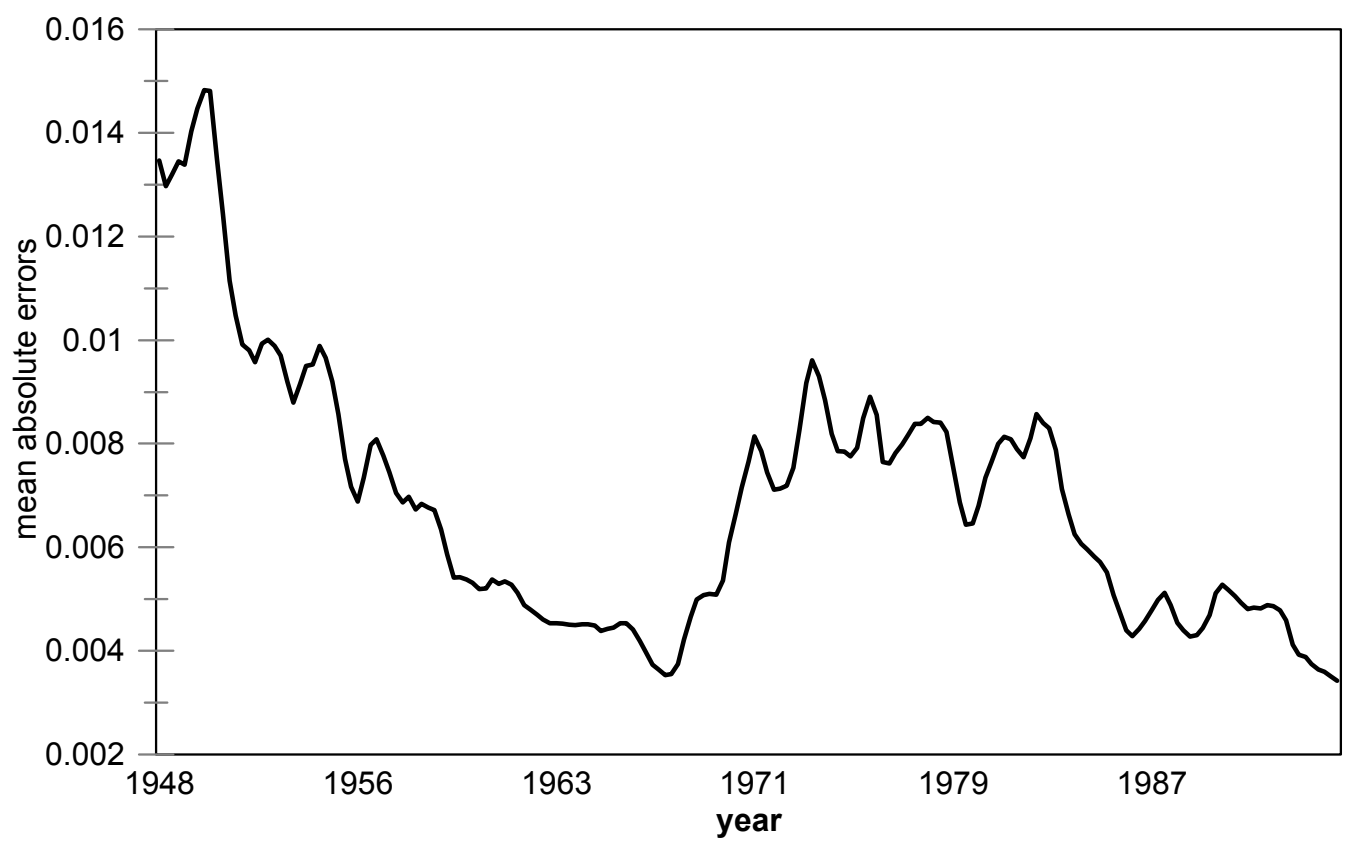

Figure 7b: Aggregate Employment Regression Standard Errors Divided by the State Mean Absolute Errors

(38 states, 12 quarter moving average)

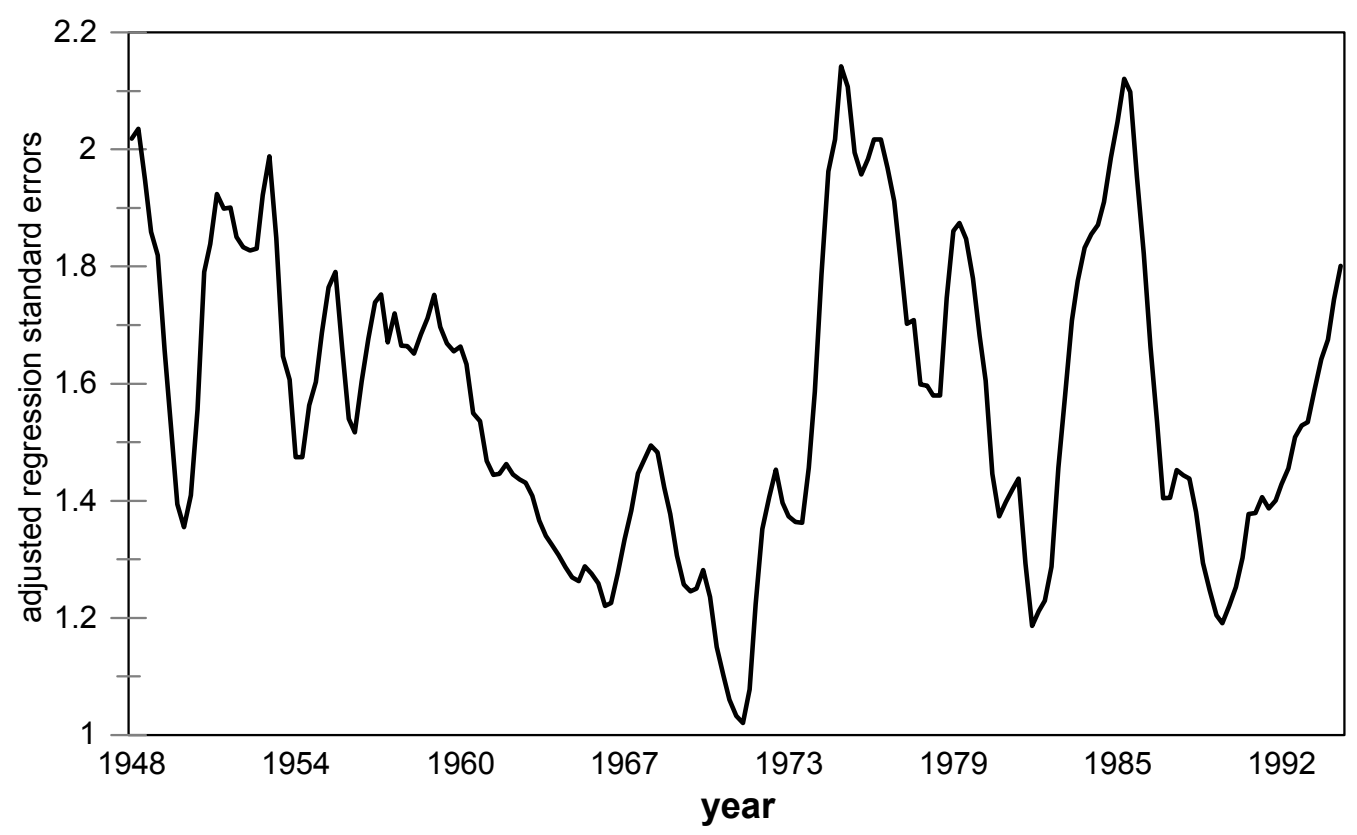


Figure 8a: Volatility of Real Government Purchases

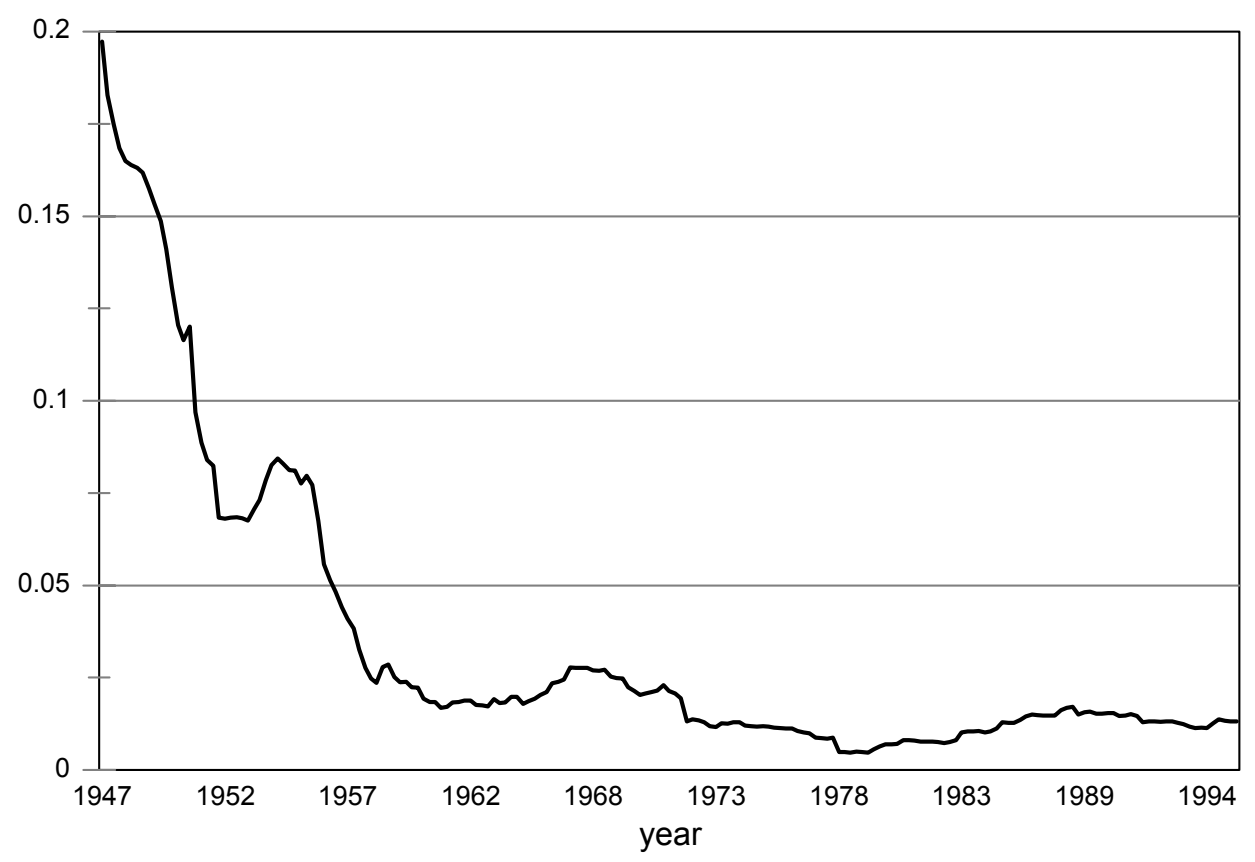

Figure 8b: Volatility of Multifactor Productivity

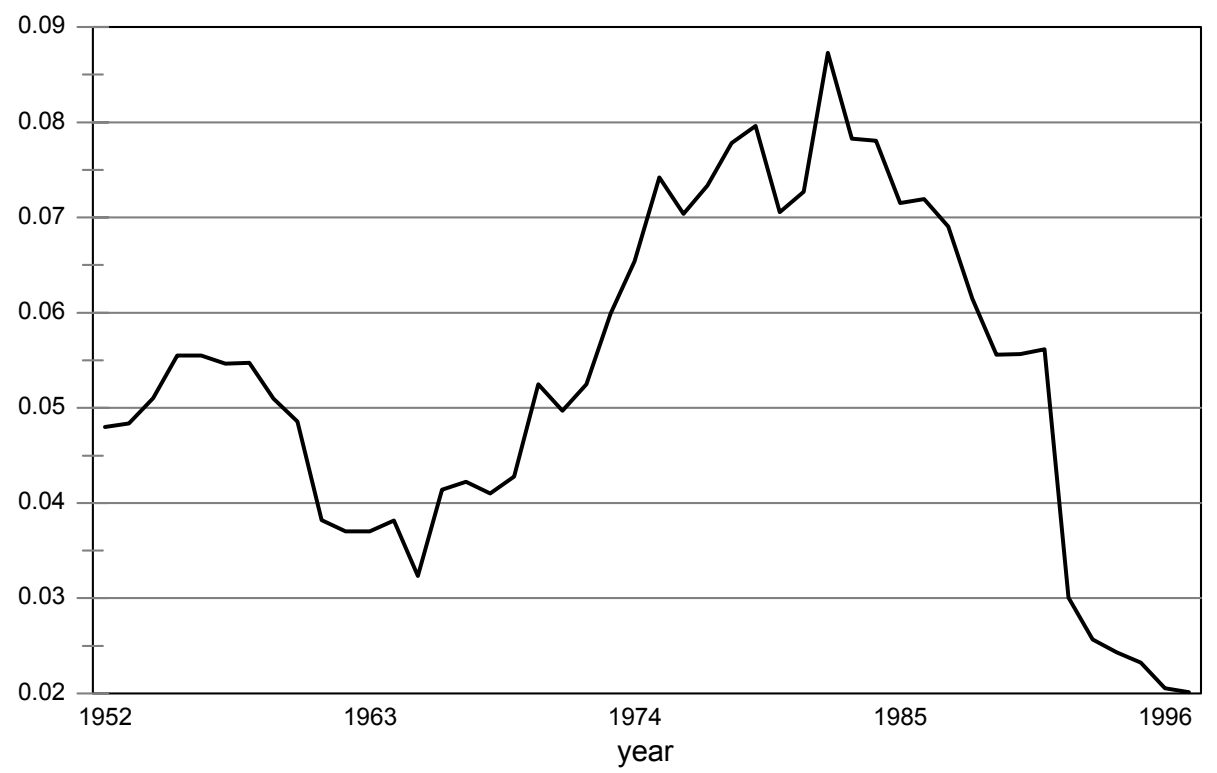

